\title{
à prova de balas? \\ necroinfâncias cariocas, violência de estado e filosofias da rua
}

\author{
diego dos santos reis 1 \\ universidade federal da paraíba, joão pessoa, paraíba, brasil \\ orcid id: https:/ / orcid.org/0000-0001-6977-7166
}

resumo

O ensaio objetiva refletir sobre os impactos da violência de Estado nas vidas e infâncias negras. Nas andanças pela cidade do Rio de Janeiro e nas trilhas teóricas propostas por pensadores/as antirracistas e decoloniais, discute-se os impactos e desafios do racismo nos itinerários formativos e existenciais de corpos racializados, atravessados pela necropolítica pública que fornece as premissas do governo pedagógico das infâncias e adolescências periféricas nas grandes cidades brasileiras. A partir do encontro com M., 11 anos, que vende chicletes no entorno de uma estação carioca de trem, problematizam-se as vulnerabilidades produzidas e as violações sistemáticas aos direitos humanos de crianças negras, que obstaculizam a justiça racial no país, em face da conversão permanente das diferenças em desigualdades inferiorizadas. A violência dessa injustiça, seguindo o argumento desenvolvido no texto, culmina por operar o reforço do vilipêndio e da naturalização das iniquidades raciais contra populações historicamente inferiorizadas pela sanha colonial. Aponta-se, ademais, para a necessidade de pensar as infâncias negras desde o território, com vistas a problematizar iniquidades e disparidades que persistem. Conclui-se, por fim, que a captura e nulificação das infâncias negras é um projeto de Estado

pautado por práticas de subjetivação criminalizantes e estereotipadas, que brutalizam os corpos e desumanizam vidas negras.

palavras-chave: necropolítica; infâncias negras; violência de Estado; racismo; necroinfâncias.

\section{bulletproof? \\ cariocas' necrochildhoods, state violence and street's philosophies}

abstract

This essay aims to reflect on the impacts of state violence upon black lives and childhoods. In the wanderings through the city of Rio de Janeiro and in the theoretical trails proposed by antiracist and decolonial thinkers, we discuss the impacts and challenges of racism in the formative and existential itineraries of racialized bodies, crossed by the public necropolitics that provides the premises of the pedagogical government of peripheral childhoods and adolescences in large Brazilian cities. From the bumping into M., 11 years old, who sells chewing gum in the surroundings of a train station in Rio de Janeiro, we problematize the vulnerabilities produced and the systematic violations of the black children's human rights, which hinder racial justice in the country, in face of the permanent conversion of differences into inferiorized inequalities. The violence of this injustice, according to the argument developed in the text, culminates in the reinforcement of the vilification and naturalization of racial inequalities against populations historically inferiorized by the colonial wrath. It also

${ }^{1}$ E-mail: diegoreis.br@gmail.com 
à prova de balas? necroinfâncias cariocas, violência de estado e filosofias da rua

points to the need to think about black childhoods from the territory, in order to problematize inequities and disparities that persist. We conclude, finally, that the capture and nullification of black childhoods is a State project, guided by criminalizing and stereotyping practices of subjectivation which brutalize bodies and dehumanize black lives.

keywords: necropolitics; black childhoods; state violence; racism; necrochildhoods.

\section{¿a prueba de balas? \\ necroinfancias "cariocas", violencia de Estado y filosofías de la calle}

resumen

El ensayo pretende reflexionar sobre las repercusiones de la violencia de Estado en las vidas e infancias negras. En las andanzas por la ciudad de Río de Janeiro y en los recorridos teóricos propuestos por pensadores antirracistas y decoloniales, se discuten los impactos y desafíos del racismo en los itinerarios formativos y existenciales de los cuerpos racializados, atravesados por la necropolítica pública que proporciona las premisas del gobierno pedagógico de las infancias y adolescencias periféricas en las grandes ciudades brasileñas. A partir del encuentro con M., de 11 años, que vende chicles en los alrededores de una estación de tren en Río de Janeiro, se problematizan las vulnerabilizaciones producidas y las violaciones sistemáticas de los derechos humanos de niñas y niños negros, que obstaculizan la justicia racial en el país, ante la permanente conversión de las diferencias en desigualdades inferiorizadas. La violencia de esta injusticia, siguiendo el argumento desarrollado en el texto, termina operando un refuerzo del vilipendio y la naturalización de las inequidades raciales contra poblaciones históricamente inferiorizadas por la saña colonial. Se señala, además, la necesidad de pensar las infancias negras desde el territorio, a los fines de problematizar las inequidades y disparidades que persisten. Se concluye, finalmente, que la captura y nulificación de las infancias negras es un proyecto de Estado guiado por prácticas de subjetivación criminalizantes y estereotipadas, que embrutecen los cuerpos y deshumanizan las vidas negras.

palabras clave: necropolítica; infancias negras; violencia de Estado; racismo; necroinfancias. 
à prova de balas?

necroinfâncias cariocas, violência de estado e filosofias da rua

\author{
As coisas que não têm nome são mais pronunciadas \\ por crianças. \\ Manoel de Barros, Uma didática da invenção
}

\title{
a porta
}

“A vida na rua, tio, não é fácil. Mas não é fácil também estudar ouvindo tiro toda hora. Aí tem que escolher... ", me disse M., de 11 anos, longe de casa e da escola, em frente à Estação de Trem do Maracanã. Escolhas injustas, escalas indevidas: caminhar pela cidade do Rio de Janeiro revela expedientes inesperados. Como o encontro com M., com sua caixa de chicletes plocs, em uma das rampas do acesso ferroviário. Nem tão imprevisto, já que, revela o menino, ele percorre rampas e ruas do entorno da UERJ, de segunda a sexta-feira. Às vezes, em certas semanas, trabalha quatro dias; mais raramente, três, mas nunca aos sábados ou domingos, porque o "movimento é fraco" e são dias bons para soltar pipa e encontrar os outros meninos da Camarista Méier, favela onde mora.

Na caixa de chicletes de M. não há mágicas ou devaneios doces propiciados pelo mascar e pelas competições das maiores bolas de chiclete, que reúnem a garotada ávida em todo canto da cidade. A caixa de chiclete poderia ser também a caixa de engraxate ou a caixa de papelão que acompanham, nas ruas, as muitas crianças que atravessam a cidade, sob viadutos, calçadas e pilotis, às sombras de arranha-céus e de prédios nos quais o entra-e-sai de pessoas parece torná-las importantes, dado o acesso permitido e livre pelas portas abertas. "Ou trabalha ou não come, né, tio", me responde M., ao ser perguntado, uma vez mais, pela escola.

Em tempos de pandemia, de insegurança alimentar e de corpos chacinados nas comunidades cariocas, como a truculenta ação que culminou no assassinato de 29 pessoas na Favela do Jacarezinho, no dia 06 de maio de 2021, mesmo em vigência da liminar ADPF 6352, trabalhar, para muitas crianças, significa lutar junto a mães, avós e

\footnotetext{
2 Em agosto de 2020, o Supremo Tribunal Federal (STF) referendou a decisão liminar que proíbe operações policiais em favelas e comunidades do Rio de Janeiro durante a pandemia do novo
} 
à prova de balas? necroinfâncias cariocas, violência de estado e filosofias da rua

irmãs/os, para garantir a subsistência. Há muito que as políticas públicas voltadas à garantia dos direitos básicos de crianças e adolescentes e a realidade nua e crua parecem experimentar certo descompasso. Talvez esbarrem em planejamentos burocráticos - ou na falta deles... - de economistas mirabolantes, "inclinados a confundir as coisas da lógica com a lógica das coisas" (Bourdieu 1998, p. 3). E da ilógica ordem que, no vale tudo cotidiano do "custe o que custar", opta, deliberadamente, por pagar o preço da morte e do desamparo de muitos ao custo do superávit financeiro para poucos.

A lógica da rua é outra. Espaço de trânsito e de fluxos urbanos, as curvas e linhas que cortam a cidade desvelam suas margens, tensões e contradições, materializadas também nas portas que abrem e fecham e demarcam posições - quem está dentro e quem está fora. Travessias afetivas para alguns; travessias de sustento, para outros; atravessamentos suspeitos, compulsórios ou libertários para outros tantos. Mas, aqui, não há espaço para qualquer romantização. Não há fuga ou passagens escondidas nessa cidade que não exponham a complexidade das relações de poder e de dominação que se instauram em cada esquina, travessa ou avenida. E os plocs nas mãos de M. podem ser também os estampidos de rajadas de tiros que irrompem na cidade, inadvertidamente, e atravessam os corpos, deixando-os estendidos ao chão, perfurados, com suas caixas, histórias e sonhos a escorrerem no asfalto quente.

M. me diz que trabalha em uma área permitida e que, naquele lugar, ele pode ficar. Ali, seu reduto, conhece as pessoas, os comerciantes e até os seguranças do Metrô e do Trem, que reconhecem o seu trabalho. O que não significa não ter passado por situações difíceis. Terríveis mesmo, "de meter medo". Por isso, está sempre atento. Observa tudo. Ouve, com ouvidos bem abertos, todas as conversas, sons de objetos, o vaivém dos trens e dos carros. $\mathrm{E}$, mesmo que as pessoas escondam seus celulares

coronavírus. Salvo em situações excepcionais, cuja justificativa por escrito torna-se imprescindível, além da comunicação ao Ministério Público, as operações estariam suspensas, dados os riscos de contágio por covid-19 às populações vulnerabilizadas, em locais com notória carência de investimentos públicos em saneamento básico. Todavia, desde a decisão em torno da Arguição de Descumprimento de Preceito Fundamental, ADPF 635 - "ADPF das Favelas" -, já foram contabilizadas quase mil mortes cometidas por policiais até março de 2021, segundo os dados do Instituto de Segurança Pública (ISP). 
apressadamente quando ele se aproxima, isso não o deixa triste, porque a cidade é violenta e "todo mundo quer um celular novo". Ele também sonha com um MotoG novo, revela, daqueles com jogos, música e tudo mais. Um dia, quem sabe, não ganha de presente de alguém que não queira mais... Um amigo da antiga escola mesmo, F., possuía dois aparelhos. Quando não precisar de ambos, ele poderá comprar mais barato da mão dele - "celular do bom é coisa cara".

O universo do consumo e seus imperativos categóricos não deixam de moldar o universo do desejo das crianças e dos adolescentes. Diante do tempo acelerado e do apelo dos aparatos tecnológicos, de modo especial, a posse ou não desses dispositivos é o que confere a muitos/as deles/as a "cidadania digital" tão almejada, como modo de reconhecimento e de pertença a uma comunidade de iguais. Lembro-me de uma passagem de Frantz Fanon em Os condenados da terra, na qual o pensador afirma que: “esse mundo hostil, pesado, agressivo porque rejeita com todas suas asperezas a massa colonizada, representa não o inferno do qual se desejaria afastar-se o mais rapidamente possível, mas um paraíso ao alcance da mão, protegido por terríveis cães de guarda" (Fanon, 2005, p. 69). O mundo do colono, ainda que hostil, suscita a inveja da parte dos colonizados, porque lhes promete a miragem de um oásis de tranquilidade e plenitude, que em tudo se contraporia às mazelas da vida cotidiana do colonizado. Não raro, a liberdade de circulação prometida e desejada pelas crianças em situação de rua aparece condicionada ao status de quem possui os recursos, materiais e simbólicos, para atravessar as portas. Portas são fronteiras bastante reais, nada imaginárias. São fronts de guerra também entre espaços de permissão e negação; da entrada, da saída e da barreira que impede os fluxos indesejados de adentrarem o "paraíso". Ou, talvez, sejam as portas do inferno, com seus círculos viciosos, por onde caminha a "perdida gente", com toda esperança deixada nos frontões da entrada. Portas mágicas, giratórias, coloridas são protegidas por "terríveis cães de guarda" - os porta-vozes da ordem e do progresso. Portanto, nenhuma entrada.

\section{janelas de fendas}


à prova de balas? necroinfâncias cariocas, violência de estado e filosofias da rua

Se os olhos são as janelas da alma, como se diz popularmente, os olhos de M. refletiam o mundo saturado de imagens, apelos e estímulos que, furiosamente, disputam sentidos, percepções e modos de vida. Pequenas portas, janelas abertas para outras paisagens, frestas que fitam a vida besta que caminha apressada nos trens e metrôs da cidade: "por uma só fresta | entra toda a vida | que o sol empresta", sussurra Alice Ruiz. Mas entra também a morte, produzida como projeto de Estado, de governo e de nação, em territórios onde a austeridade segue pautando políticas públicas e institucionais enquanto diretriz de aniquilação direcionada, com especial virulência, àqueles/as que encarnam não o mal radical, mas o mal a ser erradicado a balas.

As experiências de sociabilidades violentas e de direitos violados marcam não apenas a vida de M., mas de um contingente expressivo de crianças e adolescentes nas cidades brasileiras. Nos subúrbios, periferias e margens dos grandes centros urbanos, as balas "perdidas" seguem, certeiras, ao encontro de corpos negros. Atravessam os corpos e dilaceram famílias inteiras. Interrompem trajetórias, histórias e rotinas daqueles/as que, sequestrados/as de si, buscam a justiça como último apelo à memória de quem foi desaparecido/a de casa e não mais retornará. M. me conta que já apanhou da polícia uma vez. E que tem medo dos cachorros que, nos dias de jogo no Maracanã, acompanham os homens nas entradas do trem desde cedo. Os cães são brabos, rosnam, "não gostam de criança". Os cães, atentos, obedecem às ordens e, se estão ali, é para que a sua presença relembre que toda desordem será castigada. Mastigada. Mordida pelas forças dos agentes da lei e da lei das agências que, diante de M., afirmam o seu não-ser, o seu não poder-ser como imperativo categórico.

As metrópoles não são pensadas para crianças (Araújo, 2018; Gomes \& Gouvea, 2008). Tampouco se permitem ser pensadas por crianças. Por crianças negras que, desde cedo, compreendem os sentidos nefastos consolidados pela racialização de seus corpos e existências. As portas dos ônibus se fecham; os rostos dos homens e as bolsas das senhoras, também. O tic-tac das travas dos carros ressoa a máxima tensão e a elevação das barreiras - blindadas, inacessíveis, como a vida secreta do interior dos prédios chiques, dos bancos e contos de fadas de pessoas brancas, com seus happy end. 
Os gestos de violência racial, como escreveu Fanon (2005), inscrevem-se na lógica da aniquilação, da clausura, do desejo de destruição que embrutece e nega a humanidade de quem, proscrito do círculo dos eleitos, converte-se em resto, em morto-vivente (Mbembe, 2018). Concomitante a isso, o "processo persistente de produção da indigência cultural" (Fanon, 2008, p. 97) e da difusão das matrizes eurocêntricas do saber/poder, compreendidas como superiores, assegura a destituição de formas de vida, pensamento e experiências extra-ocidentais, que resulta na epidermização da inferioridade (Fanon, 2008, p. 28).

As modalidades de produção da morte-em-vida são diversas. É Fanon, ainda, que relata a experiência do confronto com o medo de uma criança que, ao fixar o olhar em seu corpo, aponta e enuncia: "mamãe, um preto!". Fanon (2020, p. 126) paralisa: "Explodi. Eis aqui os estilhaços recolhidos por um outro eu". Os cacos, custosamente, são ajuntados. Nenhuma sutura possível. As fissuras marcam a subjetividade, o corpo, os afetos, a consciência. Oxalá fosse possível refazer com perfeição esse si-mesmo despedaçado, desintegrado. M. me conta que está acostumado com a vida nas ruas, com os olhares mal-encarados, com a confusão que fazem todos os dias, como se ele fosse bandido. Roubaram-lhe os dias da infância; surrupiaram-lhe o sorriso que, raro, ainda é esboçado de tempos em tempos, com hesitação. Nesse lugar de passagem, em frente à entrada do transporte público ferroviário, socialmente encarado como excedente, suas cicatrizes falam - no rosto, nos braços, nos pés. E seus estilhaços denunciam a ordem intolerável que segue definindo descartes e derramamentos; quem pode existir plenamente e quem é lançando no quarto de despejo de uma cidade feroz:

Em grande medida, a raça é uma moeda icônica. Ela aparece no desdobramento de um comércio - o de olhares. É uma moeda cuja função é converter o que se vê (ou aquilo que se decide não ver) em espécie ou símbolo, dentro de uma economia geral dos signos e das imagens a serem trocados, que circulam, que atribuímos ou não valor, e que autorizam uma série de juízos e atitudes práticas (Mbembe, 2018, p. 197).

É nesse contexto belicoso e complexo das grandes metrópoles urbanas, em que as barbáries cotidianas são naturalizadas, que conversamos sobre vivências. Sobre experiências que as filosofias da educação necessitam problematizar em suas 
à prova de balas? necroinfâncias cariocas, violência de estado e filosofias da rua

comunidades de aprendizado (hooks, 2019): pensar com as infâncias desde o território. Desde corpos-territórios que, expropriados de ser, recusam-se a desaparecer. Teimam em permanecer e em tensionar universalismos, universidades e as tramas cerzidas em solo urbano, explícitas ou por debaixo dos panos, dos sacos pretos que, de tempos em tempos, cobrem os corpos negros caídos no asfalto. Insistem também em afirmar o que, sendo invisibilizado e silenciado e negado, não deixa de denunciar, com o corpo inteiro, o que está obscenamente explícito. Pois, sabe-se que, "se há um complexo de inferioridade, ele resulta de um duplo processo: econômico, em primeiro lugar; e, em seguida, por interiorização, ou melhor, por epidermização dessa inferioridade" (Fanon, 2020, p. 25).

Duplo processo que envolve as dimensões material e simbólica, (re)produzidas por um regime racista que produz a imobilidade e a necrose que lacera o corpo e a existência de sujeitos que desviam das normas centradas em valores ocidentais de distinção e privilégio. Se “a infância é, em princípio, exposta (econômica e institucionalmente) às mesmas forças sociais que os adultos, embora de modo particular [...]" (Qvortrup, 2011, p. 207), há de se ressaltar os impactos da intensidade dessas forças nos processos (auto)formativos, identitários e existenciais, que culminam, frequentemente, por produzir silêncio, vergonha e medo. A colonialidade, enquanto fato e força determinante que incidem na constituição subjetiva de corpos e mentes, produz a subjugação das crianças ao mundo dos adultos; das mulheres aos desígnios do patriarcado; dos corpos não-brancos à branquitude hegemônica, que pauta referenciais curriculares, estéticos, éticos e epistemológicos válidos, além dos modos de vida e de pensamento verdadeiros, desejados, "sob a vigilância de um silencioso racismo epistêmico, que nega não apenas os conhecimentos produzidos por povos não brancos, mas também suas maneiras de conhecer e pensar" (Flor do Nascimento, 2020, p. 19). Em uma sociedade estruturada a partir de pressupostos legados de uma organização escravagista-colonial, cujos rastros permanecem ativos nos signos e nas práticas discriminatórias, "uma das características do racismo é a maneira pela qual ele aprisiona o outro em imagens fixas e estereotipadas, enquanto reserva para os 
racialmente hegemônicos o privilégio de serem representados em sua diversidade" (Carneiro, 2011, p. 70).

Como "problema" que emerge no campo social, as crianças negras são consideradas intrusas, desumanizadas, naturalizadas como excedente na paisagem social que as reduz a refugos do mercado, em um país no qual 85\% das crianças em situação de rua são negras, segundo pesquisa realizada pelo Centro Internacional de Estudos e Pesquisas sobre a Infância da Pontifícia Universidade Católica do Rio de Janeiro (CIESPI/PUC-Rio), em parceria com Associação Beneficente O Pequeno Nazareno (2020). A pesquisa, que incluiu 17 cidades brasileiras ${ }^{3}$ com mais de 1 milhão de habitantes, realizada no âmbito do projeto "conhecer para cuidar", revelou ainda que $88 \%$ das crianças e adolescentes em situação de rua já sofreram algum tipo de violência física, de acordo com a resposta dos/as entrevistados/as. Metade deles/as aponta agentes de segurança pública como principais autores dos atos violentos sofridos. Isto é, o Estado brasileiro é o principal perpetrador das violências endereçadas a corpos racialmente subjugados. M. sabe bem disso. Conhece essa realidade na pele. E me conta que, no viaduto onde trabalha, na porta de acesso ao trem, teme ser vítima de "alguma covardia". Evita correr ou andar apressado e não inicia nenhuma abordagem sem dizer "com todo respeito, senhor/a, eu sou trabalhador...". O enunciado não basta, porém, para evitar as abordagens constantes dos agentes da segurança pública e a apreensão de seus produtos: “a gente pede, mas eles não respeitam nada", conclui o menino.

Crianças pequenas invisibilizadas, em situação de grave ou extrema violação de direitos, sabe-se que a pandemia do novo coronavírus agravou ainda mais esse quadro de vitimização, vulnerabilidade e desproteção. Ora, por que não são planejadas e executadas políticas públicas com vistas a alterar esses números, diante das estatísticas produzidas? Por que o Estado brasileiro segue omisso em sua responsabilidade de

\footnotetext{
${ }^{3}$ O estudo foi feito nas cidades de São Paulo, Rio de Janeiro, Belo Horizonte, Porto Alegre, São Luís, São Gonçalo, Brasília, Salvador, Fortaleza, Manaus, Curitiba, Recife, Belém, Goiânia, Guarulhos, Campinas e Maceió (Centro Internacional de Estudos e Pesquisas sobre a Infância/PUC-Rio; Associação Beneficente O Pequeno Nazareno, 2020).
} 
à prova de balas? necroinfâncias cariocas, violência de estado e filosofias da rua

assegurar à criança e ao adolescente, "com absoluta prioridade, o direito à vida, à saúde, à alimentação, à educação, ao lazer, à profissionalização, à cultura, à dignidade, ao respeito, à liberdade e à convivência familiar e comunitária, além de colocá-los a salvo de toda forma de negligência, discriminação, exploração, violência, crueldade e opressão" (Brasil, 1990)? Talvez porque, nas trilhas de Mbembe (2018b, p. 18), "na economia do biopoder, a função do racismo é regular a distribuição da morte e tornar possíveis as funções assassinas do Estado". Desordenar esse enunciado exige produzir fendas e denunciar a perversidade corrente da empresa colonial: criança não é de rua!

\section{infâncias negras $x$ infantarias}

Nos últimos decênios, inúmeros estudos e pesquisas têm produzido importantes deslocamentos de perspectivas sobre definições e funções que as diferentes experiências e formas de infância assumem na Améfrica Ladina (Gonzalez, 2020). Ao pluralizar a compreensão das infâncias que orienta esses estudos, desvela-se o alargamento não só semântico da categoria, mas também o reconhecimento da heterogeneidade de construções sociais que, em distintos espaçostempos, configuram ontologicamente seu tratamento e suas formas. Conforme Kohan (2003, p. 42), “a infância não é apenas o objeto educacional de nossos ideais. Como imagem de afirmação de novidade, de indeterminação, de liberdade, a infancia é uma figura do porvir que nenhuma educação que seja sensível a essa novidade pode antecipar".

Se o reconhecimento dessa diversidade de modos de ser, pensar, viver e atribuir valor semântico a diferentes experiências e formas das infâncias expande itinerários de pesquisa e oferece pistas para redimensionar os estudos antropológicos e filosóficos das infâncias, de outro lado, a superação da imagem e da ideia de "criança universal" segue desafiando as matrizes coloniais e patriarcais da epistemologia hegemônica. A dominação epistêmica dessa construção, não raro, oferece as premissas para políticas públicas de assistência e educação, desconsiderando as especificidades socioculturais de grupos e comunidades tradicionais e periféricas. Ao verticalizar a imagem da "criança universal" a partir de parâmetros e ideários exclusivamente 
euronorcentrados, rejeita-se a possibilidade do encontro com sujeitos e práticas culturais que tensionam os paradigmas geopolíticos dominantes.

Pela voz de Uã Flor, me aproximo do trabalho de Flaésio Pereira da Silva Jr. Ao tematizar práticas pedagógicas e relações mórbidas que ceifam, cotidianamente, vidas negras, os pensadores chamam atenção para a urgência da tarefa de desmantelar a lógica colonial e as necropedagogias que desencantam mundos e restringem possibilidades de ser, de sentir e de existir, consolidando o que Azoilda Loretto da Trindade (2002, p. 9) chama de morte em vida:

Este acontecimento tornou-se emblemático de um ciclo que acredito ser respaldador de preconceitos: a gente olha mas não vê; a gente vê mas não percebe; a gente percebe, mas não sente, a gente sente, mas não ama e, se a gente não ama a criança, a vida que ela representa, as infinitas possibilidades de manifestação dessa vida que ela traz, a gente não investe nessa vida, e se a gente não investe nessa vida, a gente não educa e se a gente não educa no espaço/tempo de educar, a gente mata, ou melhor, a gente não educa para a vida; a gente educa para a morte das infinitas possibilidades. A gente educa (se é que se pode dizer assim) para uma morte em vida: a invisibilidade.

A produção da invisibilidade, entendida como morte-em-vida, atesta a potência de aniquilação da hipertrofia das possibilidades de manifestação da vida expressa pelas crianças. Com Renato Noguera (2020), a estratégia de enfrentamento ao intolerável, em legítima defesa das infâncias negras, ganha os contornos da luta contra as necroinfâncias. A manutenção do padrão de violência e abuso infantil, autorizados e praticados pelo Estado brasileiro, caminha na direção da supressão do direito à infância de crianças negras, compreendidas como "menores", categoria que respalda a criminalização e o assassinato de vidas programadas para desaparecer. Veja-se, por exemplo, a manchete de jornal que traz em sua capa a notícia de que "menor de 10 anos mata criança de 5". Evidencia-se que a infância é negada a crianças racializadas. E que a universalidade da infância esbarra naquilo que Cassin (2019) destaca quando afirma que o universal é sempre universal de alguém, ressaltando sua função política segregativa. Quem é o "menor"? Quem é a criança?

Infâncias violadas, crianças alvejadas por balas que não são perdidas, mas direcionadas aos corpos-alvo. A necroinfância é a política de morte endereçada ao 
à prova de balas? necroinfâncias cariocas, violência de estado e filosofias da rua

extermínio de crianças negras, físico e simbólico, a partir de um "conjunto de práticas, técnicas e dispositivos que não permitem que as crianças negras gozem a infância" (Noguera, 2020, s.p.). Incluso, aí, toda categorização que tipifica "menores infratores" ou "em conflito com a lei" a partir da reação estatal ao que é categorizado como atos infracionais - da advertência à internação. As ditas medidas socioeducativas, previstas no Artigo 112 do Estatuto da Criança e do Adolescente (ECA), substituem as penas e castigos formalizados nos antigos Códigos de Menores de 1927 e 1979. O dispositivo legal, contudo, não logra desconstruir a mentalidade punitiva dos operadores do direito, que (ab)usam das medidas de internação com a finalidade de penalizar sujeitos inimputáveis. Atos infracionais convertem-se em crimes e medidas socioeducativas, em penas a serem cumpridas pelas crianças e jovens, em regimes diferenciados, em função do grau de periculosidade e dos riscos que estes potenciais criminosos representam à sociedade, na medida em que: "os pobres permanecem vistos como infratores em potencial e, por conseguinte, como delinquentes emergentes" (Passetti, 2006, p. 367).

A seletividade do sistema penal, portanto, assegura a aplicação das penas impingidas pelos "desvios de conduta". Alguns são encaminhados para instituições de confinamento e assistência social; outros, ao poder médico e às autoridades $p s i$, para que sejam corrigidas e prevenidas as condutas delituosas. A severidade da pena varia conforme a ameaça instanciada nesse corpo à coletividade, que tem no marcador racial um signo determinante para criminalização e eliminação dos sujeitos que encarnam o mal a ser extirpado. As representações sociais racistas, deste modo, têm a função de reiterar as imagens da negrura atreladas à brutalidade, à ameaça e à morte, para a naturalização da violência e da invisibilidade social.

Na contramão de diretivas nacionais e internacionais, como a Convenção dos Direitos da Criança (CDC), adotada pela Assembleia Geral da Organização das Nações Unidas e ratificada por 196 países, em vigor desde 2 de setembro de 1990, nega-se, com respaldo do racismo institucional, a proteção às crianças negras e periféricas, frequentemente designadas como "pivetes". Em seu Artigo 2 ${ }^{\circ}$, a Convenção dispõe que 
“os Estados-Partes devem adotar todas as medidas apropriadas para assegurar que a criança seja protegida contra todas as formas de discriminação ou punição em função da condição, das atividades, das opiniões manifestadas ou das crenças de seus pais, representantes legais ou familiares" (ONU, 1990). Essas medidas protetivas, contudo, não só têm sido negligenciadas, como o Estado torna-se, reiteradamente, agente perpetrador de violações sistemáticas aos direitos da criança negra e de violências que sequestram suas infâncias.

Se as infantarias sanguinárias seguem fazendo "justiça" para o alívio dos "cidadãos de bem", as balas não erram seus desígnios: destroçam famílias inteiras, atravessam o peito das mães, das avós e das tias, mulheres que denunciam as violações que devastam gerações, destroem trajetórias, interrompem gestações. Histórias cessadas pelos projéteis de armas de fogo, que concretizam o terrorismo de Estado brasileiro. O que reafirma, perversamente, o que em um conto como Pai Contra Mãe é enunciado por Machado de Assis (2015, p. 627), no contexto escravagista, com a seguinte inscrição: "nem todas as crianças vingam". Sonhos, vidas e percursos são interrompidos pelo terror autorizado de Estado, sem grande sensibilização, comoção ou luto público (Reis, 2020).

Diante desse cenário, como efetivar as obrigações previstas pelo Artigo $6^{\circ}$ da $\mathrm{CDC}$, que podem ensejar a responsabilidade internacional dos Estados signatários da Convenção, na medida em que dispõem que "os Estados-Partes reconhecem que toda criança tem o direito inerente à vida", tendo o dever de "assegurar ao máximo a sobrevivência e o desenvolvimento da criança" (ONU, 1990)? O Estado brasileiro, dentre as muitas contradições que o fundamentam, exime-se de cumprir as suas obrigações legais, o que assegura a manutenção do "estado de coisas inconstitucional" vigente, no qual:

[...] Pessoas negras, inseridas em contextos de morte social, são descartáveis e são objetos de violência gratuita independentemente do que fazem. O mundo da política, da sociedade civil, do estado-império é um mundo cuja lógica depende da morte negra, social e física. A pessoa negra, por definição, morre violentamente sem causa. "Amarildo desapareceu a caminho de casa." Ou "Cláudia estava indo comprar pão e foi morta pela polícia." E outros tantos casos. Previsíveis 
em sua imprevisibilidade. Imprevisíveis em sua previsibilidade. Todos paradigmáticos: emblemáticos da lógica social antinegra, do mundo antinegro (Vargas, 2017, p. 99).

Nas topografias da violência, a geografia do extermínio marca infâncias fraturadas e crianças desaparecidas, fulminadas pelos agentes repressivos do Estado ou por grupos civis armados. A luta pela sobrevivência é também, nas tramas da memória e na reivindicação por justiça e equidade, politização da morte e dos corposalvos das necropolíticas públicas. Como o de Ágatha Vitória Sales Félix, de 8 anos, vitimizada em setembro de 2020 pelo disparo da arma de fogo de um agente de Estado, no Complexo do Alemão, no Rio de Janeiro. Em seu enterro, Airton Félix, avô de Ágatha, questionaria em seu discurso o "projeto de futuro" reservado às crianças periféricas e negras na cidade:

Sabe qual era a arma que tinha dentro da mochila da minha neta? Lápis, caderno, apontador, livro. Tinha um simulado que ela fez nessa semana e tirou 7! Essas eram as armas que a Ágatha gostava de usar. Ela tinha um futuro, ia crescer e entrar na faculdade. Mas o estado não quer isso. E se continuar dessa forma, o que vai acontecer?4

Segundo o Fórum Brasileiro de Segurança Pública (FBSP, 2021), em 2020, ao menos 267 crianças de 0 a 11 anos e 5.855 crianças e adolescentes de 12 a 19 anos foram vítimas de mortes violentas intencionais no país. Os registros aterrorizam: trata-se de 6.122 crianças e adolescentes vitimados por causas violentas. E nem a pandemia do novo coronavírus foi capaz de refrear esses números, pois, em comparação com o ano de 2019, o número é 3,6\% superior aos dados divulgados no ano passado. Em média, nos últimos dois anos, 17 crianças e adolescentes morrem por dia no Brasil; 1 vítima a cada duas horas.

Se, de um lado, os crimes letais que mais acometem crianças e adolescentes de 0 a 19 anos são os homicídios dolosos (82,4\%), causados por armas de fogo, de outro, mais de 70\% das vítimas são negras, isto é, pretas ou pardas. Soma-se a isso o fato do

\footnotetext{
${ }^{4}$ Zarur, Camilla; Oushana, Giselle. “A arma que ela gostava de usar era lápis, caderno, redação nota 10", diz avô durante enterro de menina baleada no Alemão. Disponível em: https://oglobo.globo.com/rio/a-arma-que- ela-gostava-de-usar-era-lapis-caderno-redacao-nota-10diz-avo-durante-enterro-de-menina-baleada-noalemao23966403. Acesso em: 12 jun. 2021.
} 
aumento da desigualdade entre grupos raciais "à medida que a idade das vítimas avança. Quanto mais velha for a vítima, maior a probabilidade de ela ser negra e do sexo masculino" (FBSP, 2021, p. 230). Fato é que a maior parte das mortes sequer são noticiadas na grande mídia, mas inflam as estatísticas oficiais. Nesse contexto, tal como corroboram os dados $15^{\circ}$ Anuário Brasileiro de Segurança Pública (FBSP, 2021), a desigualdade racial ligada à letalidade policial retrata o déficit de direitos fundamentais da população negra no país.

Cabe destacar ainda que as desigualdades sociais explicitam os diferentes modos e compreensões de lidar com a pandemia no país. O contexto pandêmico escancara as assimetrias e iniquidades, com recortes de classe, raça e gênero bem salientados. As famílias e as escolas experimentam os impactos em suas dinâmicas e atividades, o que tem exigido reorganização de ações e estratégias, em um cenário no qual as variáveis socioeconômicas, raciais e territoriais definem possibilidades e prejuízos às demandas de desenvolvimento específicas de cada faixa etária. Não raro, as atividades designadas às famílias para serem levadas a cabo com as crianças, por exemplo, esbarram nos contextos de vida diversos e adversos, que impossibilitam sua realização. À vista disso, reitera-se que:

[...] considerar a família como mediadora pedagógica do desenvolvimento pleno das crianças, frente à desigualdade social brasileira, as sobrecarrega e desrespeita a sua realidade, já que muitas destas famílias não dispõem nem de condições básicas para manter uma vida digna, tampouco de um repertório didático-pedagógico alinhado às especificidades etárias dos bebês e das crianças pequenas. De igual modo, tal medida descaracteriza a ação pedagógica das/os profissionais de educação infantil, que possuem formação específica que lhes permite atuar, de modo intencional nos processos de aprendizagem e desenvolvimento de forma integral. Assim, qualquer proposta que permita a legitimação de açães educativas (educação domiciliar, ensino remoto, adoção de sistemas apostilados, dentre outras) que reforcem, ainda mais, as desigualdades sociais e educacionais entre as crianças e suas famílias deve ser evitada a todo custo [...] (Mieib, 2020, s.p.).

A desigualdade no acesso à escolarização e à permanência culmina por agravar as disparidades entre brancos e negros em todas as etapas da educação formal. Para Noguera (2021, s.p.), em face aos dispositivos de morte, institucionais ou não, que 
à prova de balas? necroinfâncias cariocas, violência de estado e filosofias da rua

impedem que as crianças negras gozem da infância, seria preciso, "urgentemente, de um pacto político-social que garanta a infância das crianças negras".

\section{considerações sem finais}

A porta, as janelas de fendas, as infâncias amefricanas que se opõem às infantarias. Infâncias que promovem rasgos, fissuras e tensões nas matrizes de inteligibilidade dominantes e em seus repertórios metodológicos, políticos, epistêmicos e pedagógicos. A necessária repactuação político-epistêmica e a expansão de categorias analíticas direcionadas à pesquisa e aos estudos das infâncias, em chave decolonial, precisam considerar os imaginários, as representações e as experiências de vida, cuidado e criação que se erigem a partir e com os corpos negros. Crianças negras que, entre resistências e negociações, reinventam dinâmicas sociais de pertença, de sobrevivência e de (auto)afirmação da vida como potência que resiste a qualquer negatividade. Longe de ser mera fase de transição, tempo de passagem ou estágio preparatório, a infância, tal como compreendemos, colapsa concepções periódicas ou cronológicas, caixas etiquetadas e linhas do tempo progressivas, prefiguradas.

Não se trata, porém, do processo de infantilização que marca, historicamente, os corpos negros desde o olhar da branquidade e do eurocentrismo que, em nome da suposta incapacidade dos sujeitos negros, conferiu a si o poder de tutela, legitimado pela diferença epidérmica como signo de invalidação do epistêmico. Antes, a compreensão filosófica da infância em uma afroperspectiva aproxima-se do que Noguera (2019b) nomeia de cosmosentidos, que tornam possíveis a reelaboração das experiências de vida a partir da descolonização das relações raciais, educacionais e sociais, sem deixar de apontar os imensos desafios diante da "necessidade de enfrentar

o histórico racista que conformou nosso pensamento e práticas sobre a sociedade brasileira" (Flor do Nascimento, 2020, p. 97).

Seguindo os passos de M., levado pelo compasso de suas andanças, penso que a necessária descolonização e o enfrentamento às necroinfâncias, orientadas para aniquilação existencial das crianças negras, impõem a resistência ativa à matriz colonial 
das relações de poder/saber (Reis, 2020b). À prova de balas, das balas que atravessam e fulminam os corpos brincantes, a educação como encantamento fecha o corpo para os cídios que, no solo da diáspora, dão a tônica das políticas de morte - dos livros didáticos e currículos às balas de fogo achadas em corpos negros. É sabido que o "racismo, assim como misoginia, machismo, lgbtfobia, adultocentrismo, discriminação de pessoas com deficiências e todas as formas de opressão não têm soluções mágicas. Mas nossa aposta teórica é de que as alternativas passam pela infancia. Por essa infância que descrevemos como condição de experiência humana (Noguera, 2019, p. 66). Com Noguera, considero que as rotas decoloniais, que reposicionam as relações de poder/saber, exigem deslocamento de universalismos abstratos e agenciamento das resistências cotidianas contra tudo o que fere de morte e impede a sutura das feridas coloniais do racismo, do sexismo e de outros ismos que definem lugares, espaços e posições hierarquizadas. É preciso, no enfrentamento às necroinfâncias e ao genocídio negro que começa no ventre, produzir rachaduras, sismos e ruídos que engendrem vazamentos insuspeitos: o corpo vivo dos combates, a coreografia das esquivas. Tarefa à qual nos convoca também Iago Passos (2017, p. 158), em 2 poemas sobre erês e um terceiro:

$$
\begin{gathered}
\text { a criança veio me devolver algo que deixei cair } \\
\text { eu era erêe prometi sempre ter olhos de erê } \\
\text { o dono da cura me deu olhos de rever infâncias } \\
\text { lembrei, nunca mais esqueci } \\
\text { : segurar firme a voz do invisível }
\end{gathered}
$$

A voz registrada na caixa preta da vida: infâncias que vingam.

\section{referências}

Araújo, Vania Carvalho de. Pensar a cidade, as crianças e sua educação. Educação, Santa Maria, v. 43, n. 2, p. 207-222, abr./jun. 2018.

Assis, Machado de. Pai contra mãe. In:___. Obra completa em quatro volumes, vol. 2. Org. Aluizio Leite, Ana L. Cecílio e Heloisa Jahn. São Paulo: Editora Nova Aguilar, 2015. p. 621-627. Centro Internacional de Estudos e Pesquisas sobre a Infância/PUC-Rio; Associação Beneficente O Pequeno Nazareno. Projeto Conhecer para Cuidar - Relatório final do levantamento de 
à prova de balas? necroinfâncias cariocas, violência de estado e filosofias da rua

dados quantitativos e qualitativos sobre crianças e adolescentes em situação de rua e em Acolhimento Institucional como medida protetiva à situação de rua. Rio de Janeiro/Fortaleza, mai. 2020. Disponível em: http://www.ciespi.org.br/media/Publicacoes/relat_Projeto_CPC.pdf Acesso em: 15 jun. 2021.

Bourdieu, Pierre. L'essence du néolibéralisme. Le Monde Diplomatique, Paris, mar. 1998. Disponível em: www.monde-diplomatique.fr/1998/03/BOURDIEU/10167\#nh1. Acesso em: 15 mar. 2021.

Brasil. Lei n. ${ }^{\circ}$ 8.069, de 13 de julho de 1990. Dispõe sobre o Estatuto da Criança e do Adolescente e dá outras providências. Diário Oficial da República Federativa do Brasil, Brasília, DF, 16 jul. $1990 . \quad$ Disponível em: <http://www.planalto.gov.br/ccivil_03/LEIS/L8069.htm\#art266>. Acesso em: 23 jun. 2021.

Carneiro, Sueli. Negros de pele clara. In: Racismo, sexismo e desigualdade no Brasil. São Paulo: Selo Negro, 2011.

Cassin, Barbara. Elogio de la traducción: complicar el universal. Buenos Aires: Ed. El Cuenco de Plata, 2019.

Fanon, Frantz. Os condenados da Terra. Trad. Enilce Alberfaria Rocha e Lucy Magalhães. Juiz de Fora, MG: Editora UFJF, 2005.

Fanon, Frantz. Pele negra, máscaras brancas. Trad. Renato da Silveira. Salvador: EDUFBA, 2008.

Flor do Nascimento, Wanderson. Entre apostas e heranças: contornos africanos e afro-brasileiros na filosofia da educação brasileira. $1^{\text {a }}$. ed. Rio de Janeiro: Edições NEFI, 2020.

Fórum Brasileiro de Segurança Pública - FBSP. Anuário Brasileiro de Segurança Pública 2021. São Paulo, Ano 15, 2021. Disponível em: https://forumseguranca.org.br/wpcontent/uploads/2021/07/anuario-2021-completo-v6-bx.pdf Acesso em: 10 jul. 2021.

Gomes, Ana Maria Rabelo; Gouvea, Maria Cristina Soares de. A criança e a cidade: entre a sedução e o perigo. In: Debortoli, José Alfredo; Martins, Maria de Fátima; Martins, Sérgio (Org.). Crianças na metrópole. $1^{\text {a }}$. ed. Belo Horizonte: UFMG, 2008. p. 45-71.

Gonzalez, Lélia. Por um feminismo afro-latino-americano: ensaios, intervenções e diálogos. Org. Flávia Rios \& Márcia Lima. 1ª . ed. Rio de Janeiro: Zahar, 2020.

hooks, bell. Ensinando a transgredir: a educação como prática da liberdade. Trad. Marcelo Brandão Cipolla. 2a . ed. São Paulo: Editora WMF Martins Fontes, 2019.

Kohan, Walter. O. "O ensino da filosofia frente à educação como educação". In: Gallo, Sílvio; Cornelli, Gabriel; Danelon, Márcio. Filosofia do ensino de filosofia. Petrópolis, RJ: Vozes, v. 7, 2003.

Mbembe, Achille. Crítica da razão negra. Trad. Sebastião Nascimento. São Paulo: n-1 edições, 2018.

Mbembe, Achille. Necropolítica: biopoder, soberania, estado de exceção, política de morte. Trad. Renata Santini. São Paulo: n-1 ediç̃oes, 2018b.

Movimento Interfóruns de Educacạao Infantil do Brasil - MIEIB. Posicionamento público do Movimento Interfóruns de Educação Infantil do Brasil (MIEIB) relativo à proposta de parecer do Conselho Nacional de Educação (CNE) sobre reorganização dos calendários escolares e atividades pedagógicas não presenciais durante o período de pandemia da COVID-19. Brasília, abril 2020. Disponível em: https://www.mieib.org.br/wp-content/ uploads/2020/04/POSICIONAMENTO-MIEIB-PARA-O-CNE-FINAL-19.04.2020.pdf. Acesso em: 07 jun. 2021. 
Noguera, Renato. Crianças negras desaparecidas: até quando vamos aceitar? Portal Lunetas. Disponível em: https://lunetas.com.br/criancas-negras-desaparecidas-ate-quandovamos-aceitar/ Acesso em: 19 jun. 2021.

Noguera, Renato. Infância em Afroperspectiva: Articulaç,ões Entre Sankofa, Ndaw e Terrixistir. Revista Sul-Americana de Filosofia e Educação (RESAFE), (31), p. 53-70, 2019.

Noguera, Renato. Necroinfância: por que as crianças negras são assassinadas? Portal Lunetas. Disponível em: https://lunetas.com.br/necroinfancia-criancas-negras-assassinadas/ Acesso em: 19 jun. 2021.

Noguera, Renato. O poder da infancia: espiritualidade e política em afroperspectiva. Momento: diálogos em educação, v. 28, n. 1, p. 127-142, jan./abr. 2019 b.

Organização das Nações Unidas. Convenção sobre os Direitos da Criança, de 20 de novembro de 1989. Disponível em: http://nacoesunidas.org/docs/. Acesso em: 21 mai. 2021.

Passetti, Edson. Crianças carentes e políticas públicas. In: Del Priore, Mary (Org.). História das Crianças no Brasil. São Paulo: Contexto, 2006.

Passos, Iago. 2 poemas sobre erês e um terceiro. In: Fenati, Maria Carolina. Gratuita - Infância., v. 3. Belo Horizonte: Chão da Feira, 2017. p. 155-158.

Qvortrup, Jens. Nove teses sobre a "infância como um fenômeno social". Pro-Posições, Campinas, v. 22, n. 1, p. 199-211, abr. 2011.

Reis, Diego dos Santos. Filosofia em zona de confronto: máscaras securitárias, desejos coloniais. Teoliterária: Revista Brasileira de Literaturas e Teologias, v. 10, p. 79-98, 2020.

Reis, Diego dos Santos. Saberes encruzilhados: (de)colonialidade, racismo epistêmico e ensino de filosofia. Educar em Revista, Curitiba, v. 36, p. 1-20, 2020 b.

Trindade, Azoilda Loretto da. Olhando com o coração e sentindo com o corpo inteiro no cotidiano escolar. In: ___ Santos, Rafael dos (Org.). Multiculturalismo: mil e uma faces da escola. 3a. ed. Rio de Janeiro: DP\&A, 2002.

Vargas, João Helion Costa. Por uma mudança de paradigma: antinegritude e antagonismo estrutural. In: Flauzina, Ana Luiza Pinheiro; Vargas, João Helion Costa (Org.). Motim: horizontes do genocídio negro. Brasília: Brado Negro, 2017. p. 91-105.

recebido em: 27.07 .2021

aprovado em: 20.08 .2021 